\title{
Antivacina, fosfoetanolamina e Mineral Miracle Solution (MMS): mapeamento de fake sciences ligadas à saúde no Facebook
}

\author{
Anti-vaccine, phosphoethanolamine and Mineral Miracle Solution (MMS): \\ mapping of health-related fake sciences on Facebook
}

\section{Antivacina, fosfoetanolamina y Mineral Miracle Solution (MMS): mapeo de fake sciences relacionadas con la salud en Facebook}

Thaiane Moreira de Oliveira ${ }^{1, a}$

thaianeoliveira@id.uff.br | http://orcid.org/oooo-0002-8588-3548

Rodrigo Quinan Ribeiro Martins ${ }^{1, b}$

rodrigoquinan@id.uff.br| http://orcid.org/0000-0002-5344-0574

Janderson Pereira Toth ${ }^{1, c}$

jandersonpsc@gmail.com | http://orcid.org/0000-0002-0931-9785

${ }^{1}$ Universidade Federal Fluminense, Programa de Pós-Graduação em Comunicação. Niterói, RJ, Brasil.

a Doutorado em Comunicação pela Universidade Federal Fluminense.

b Mestrado em Comunicação pela Universidade Federal Fluminense.

${ }^{\complement}$ Graduação em Estudos de Mídia pela Universidade Federal Fluminense.

\section{Resumo}

A partir de uma abordagem multimetódos baseada em pesquisa qualitativa de observação não-participante, análise de conteúdo e técnicas de snowballing de recomendação algorítmica, a proposta deste artigo é mapear a circulação de três disputas de informação científica ligadas à saúde em páginas e grupos brasileiros no Facebook - movimento antivacina, fosfoetanolamina e Mineral Miracle Solution (MMS). Os resultados apontam para um campo de disputa no qual a autoridade científica é um valor relevante, sendo recorrentemente acionada como signo de convencimento junto ao público. Ainda, as fake sciences são um campo de disputa que envolvem 1) interesses comerciais em torno da crença em soluções rápidas e alternativas, 2) implicações jurídicas em torno do discurso pelo direito à informação e acesso a esses tratamentos alternativos, 3) sistema de reputação na busca por interseção na formulação de políticas e a alocação de recursos públicos e 4) uma descrença nas instituições epistêmicas, fazendo os sujeitos acreditarem apenas em experiências individuais baseadas no discurso de testemunho.

Palavras-chave: Fake sciences; Conflitos de interesse; Desinformação; Crise epistêmica; Facebook. 


\section{Abstract}

From a multi-method approach based on qualitative research of non-participant observation, content analysis and snowballing techniques with algorithmic recommendation, the purpose of this article is to map the circulation of three scientific information disputes related to health on pages and groups on Facebook - anti-vaccine movement, phosphoethanolamine and Mineral Miracle Solution (MMS). The results point to a field of dispute in which scientific authority is a relevant value in these spaces, being repeatedly used as a sign of convincing the public. Still, fake sciences are a field of dispute that involve 1) commercial interests around the belief in quick and alternative solutions, 2) legal implications around the discourse for the right to information and access to the alternative treatments, 3) system of reputation in the search for intersection in the formulation of policies and the allocation of public resources and 4) a disbelief in epistemic institutions, making subjects believe only in individual experiences based on the testimony discourse.

Keywords: Fake sciences; Conflicts of interest; Misinformation; Epistemic crisis; Facebook.

\section{Resumen}

Desde un enfoque de métodos múltiples basado en la investigación cualitativa de observación no participante, análisis de contenido y técnicas de snowballing con recomendación algorítmica, el propósito de este artículo es mapear la circulación de tres disputas de información científica relacionadas con la salud en páginas y grupos en Facebook: movimiento antivacunas, fosfoetanolamina y solución de milagro mineral (MMS). Los resultados apuntan a un campo de disputa en el que la autoridad científica es un valor relevante en estos espacios, y se usa repetidamente como un signo de convencer al público. Aún así, las fake sciences son un campo de disputa que involucra 1) intereses comerciales, en torno a la creencia en soluciones rápidas y alternativas, 2) implicaciones legales en torno al discurso sobre el derecho a la información y el acceso a estos tratamientos alternativos, 3) sistema de reputación en la búsqueda de intersección en la formulación de políticas y la asignación de recursos públicos y 4) una incredulidad en las instituciones epistémicas, haciendo que los sujetos crean solo en experiencias individuales basadas en el discurso del testimonio.

Palabras clave: Fake sciences; Conflictos de intereses; Desinformación; Crisis epistémica; Facebook.

Contribuição dos autores:

Concepção e desenho do estudo: Thaiane Oliveira.

Aquisição, análise ou interpretação dos dados: Thaiane Oliveira, Rodrigo Quinan, Janderson Toth.

Redação do manuscrito: Thaiane Oliveira, Rodrigo Quinan.

Revisão crítica do conteúdo intelectual: Thaiane Oliveira

Declaração de conflito de interesses: não há.

Fontes de financiamento: Conselho Nacional de Desenvolvimento Científico e Tecnológico (Bolsa Produtividade, Processo: 311258/2019-0). Fundação de Amparo à Pesquisa do Estado do Rio de Janeiro (Recém-Contratado [ARC], Processo: 253110), Coordenação de Aperfeiçoamento de Pessoal de Nível Superior (Bolsa de mestrado de Rodrigo Quinan).

Considerações éticas: não há.

Agradecimentos/Contribuições adicionais: não há.

Histórico do artigo: submetido: 15 dez. 2019 | aceito: 12 mar. 2019 | publicado: 31 mar. 2020.

Apresentação anterior: não houve.

Licença CC BY-NC atribuição não comercial. Com essa licença é permitido acessar, baixar (download), copiar, imprimir, compartilhar, reutilizar e distribuir os artigos, desde que para uso não comercial e com a citação da fonte, conferindo os devidos créditos de autoria e menção à Reciis. Nesses casos, nenhuma permissão é necessária por parte dos autores ou dos editores. 


\section{Introdução}

Nos últimos anos, tem sido recorrente uma preocupação no debate público e político sobre temas como "pós-verdade", "fatos alternativos" e "notícias falsas", tanto nos meios de comunicação como também nas discussões acadêmicas ${ }^{1,2}$. Frequentemente associados a disputas sobre a produção de verdade, as chamadas fake news podem ser associadas à contestação da informação como forma de desautorização da veracidade informacional ${ }^{3}$ ou ataques geopolíticos no qual a informação tem sido o alvo de conflitos entre potências internacionais ${ }^{4}$. Ainda que tais enquadramentos sobre a circulação de desinformação expliquem parte do fenômeno, pouco tem se discutido sobre a responsabilidade das próprias comunidades epistêmicas ${ }^{5}$ no processo de descredibilização de sua autoridade. Quando os conflitos de interesses são constantemente midiatizados, aumenta o sentimento de desconfiança da população sobre estas instituições consideradas produtoras de conhecimento socialmente legitimado e que exercem algum tipo de influência na esfera pública.

Neste espaço de disputa sobre a verdade, as teorias da conspiração e outras narrativas que se apropriam de discursos científicos emergem como um fenômeno de grande repercussão nas redes sociais digitais, sobretudo quando ocorrem acontecimentos de grande impacto para a sociedade, como na área de saúde. Movimentos como antivacina, por exemplo, vêm ganhando espaço nas redes sociais digitais, e vários grupos corroboram para que mitos em torno de campanhas de vacinação sejam propagados em diversos canais, ganhando cada vez mais adesão da comunidade não-científica, colocando em risco a saúde da população e aumentando a probabilidade para a ocorrência de surtos de doenças até então controladas. Vimos recentemente um aumento de casos de sarampo no Brasil, ocasionado por esse fenômeno de propagação de notícias falsas sobre a vacinação. Os números ${ }^{6}$ monitorados pelo Ministério da Saúde são alarmantes: 677 casos nos seis primeiros meses de 2018 e mais de 2.000 sob investigação. Este crescimento também é observado nos relatórios da Organização Mundial de Saúde que apontam para o aumento de casos de sarampo, difteria, poliomielite e síndrome de rubéola congênita ${ }^{7}$.

Para além dos movimentos antivacina, outros assuntos se tornaram presentes na agenda midiática no cenário nacional: a polêmica sobre o uso de Fosfoetanolamina - um composto químico mais conhecido como a 'pílula do câncer' no Brasil, com grande repercussão em 2016 - e sobre o uso do supositório MMS - sigla de Mineral Miracle Solution - para a cura de autismo, que em 2018 ganhou atenção da mídia após a publicação do livro da homeopata Kerri Rivera ${ }^{8}$, 'Curando os sintomas conhecidos como Autismo', a partir de pesquisas realizadas pelo astrofísico americano Jim Humble e do cientista alemão Andreas Kalcker sobre o uso de dióxido de cloro para a saúde.

Os três casos apontam para questões que envolvem conflitos de interesses entre cientistas, a indústria farmacêutica, o governo e a própria mídia, a qual exerce um papel importante na midiatização dessas controvérsias, aumentando a desconfiança da população sobre essas instituições. Para além desses atores, cuja relação com a universidade tem sido cada vez mais intrínseca, as disputas sobre a informação científica, especialmente em redes sociais, têm se tornado cada vez mais evidentes, sobretudo em função de constantes apropriações de discursos científicos para a propagação de informação que vai contra as próprias pesquisas científicas, o que tem sido chamado de fake science ${ }^{9-10}$. Nestes espaços digitais de disputa pela atenção, a influência em rede tem se tornado um valor importante para a construção de autoridade e reconhecimento junto ao público. Visibilidade, autoridade e reputação são valores sociais importantes nas redes sociais digitais ${ }^{11}$, relacionados a dinâmicas tecnossociais específicas desses ambientes, como a própria recomendação algorítmica que tende a moldar a influência dos atores junto a uma rede.

Diante do cenário apresentado, torna-se cada vez mais necessário entender o campo de disputa sobre a informação científica, buscando identificar quem são os atores, os discursos produzidos, desvelando as redes que se formam para a disseminação da desinformação científica em sites de redes sociais. Assim, a 
proposta deste artigo é mapear a circulação dessas três disputas sobre a informação (movimento antivacina, fosfoetanolamina e MMS) em páginas e grupos no Facebook, buscando identificar os canais brasileiros que disseminam as fake sciences, os tipos de conteúdo utilizados e os atores de influência nas redes que se formam a partir da recomendação algorítmica sobre a desinformação relacionada à saúde.

\section{As fake sciences: conflito de interesses e descrença institucional}

No século XIX, devido a um progresso acelerado de desenvolvimento tecnológico e industrial, a ciência foi elevada a um lugar de destaque e de prestígio como uma das principais instituições com conhecimento socialmente legitimado para atuar junto ao Estado na proposição de políticas públicas ${ }^{5}$. Contudo, este prestígio legitimado sobre a ciência, desde a década de 1970, passa a ser contestado devido à percepção

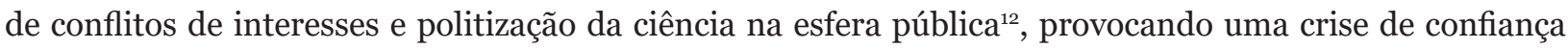
nas instituições científicas. Mooney ${ }^{13}$ aponta que esta percepção da politização da ciência passou a ser observada na década de 1970, com a ascensão de uma Nova Direita, grupo cético sobre a neutralidade científica, alinhado com o direito religioso, forte defesa nacional e proteção dos valores tradicionais.

Vivemos em um momento caracterizado pela dependência de enormes recursos financeiros, privatização e sigilo de pesquisa, mercantilização dos resultados científicos, burocratização de instituições científicas e instrumentalização da ciência, sujeitando-a a interesses extra-científicos ${ }^{14}$, próprios do capitalismo acadêmico ${ }^{15-16}$, em que há uma mudança do valor do conhecimento como bem comum para uma mercadoria a ser comercializada em benefício de grandes corporações. Tais mudanças sobre o papel da universidade têm causado complexas discussões sobre conflitos de interesses, percepção pública sobre a ciência e sobre o aumento do sentimento de desconfiança da população quanto a instituições consideradas produtoras de conhecimento socialmente legitimado.

É no meio dessa reconfiguração sobre o papel da universidade e centros de pesquisa e a entrada desses novos atores de interesses diversos para o financiamento e investigações que emergem movimentos que provocam grande preocupação mundial, sobretudo na área de saúde pública: as fake sciences. Tal como as fake news, as fake sciences podem se espalhar com tanta eficácia que, mesmo quando as informações são corrigidas, permanecem dentro do conjunto não verificado de conhecimento comum ${ }^{17}$. Mais ainda, tal como as fake news ${ }^{18}$, as fake sciences derivam de uma disputa sobre a desinformação que não surge de agentes externos ao sistema, mas está associada a uma rede complexa que envolve conflitos de interesse e declínio da credibilidade das instituições produtoras de conhecimento e de verdade - a mídia (no caso das fake news) e a ciência (no caso das fake sciences).

Segundo Grech ${ }^{19}$, as fake sciences podem ter duas origens: fraude científica ou a politização da ciência. No entanto, não se trata apenas de condutas dentro da comunidade científica, mas compreendemos as fake sciences como uma apropriação dos discursos científicos para a propagação de uma informação que vá contra as pesquisas científicas, implicando uma série de disputas em prol do controle e da verificação da informação. Nesse cenário, emergem teorias da conspiração relacionadas à ciência, pseudociências, tratamentos alternativos, entre outros discursos que vão ganhando contornos político-partidários em um momento em que o conservadorismo é evidenciado. Segundo Almeida ${ }^{20}$ este conservadorismo é observado a partir de 1) valores morais reguladores, com a retomada de questões voltadas para a valoração da nucleação tradicional, como a família; 2) vetores jurídicos e econômicos, decorrentes de lógicas liberais sobre os indivíduos, em que combinam menor presença do Estado na economia e mais regulação jurídica da moralidade pública; 3) controle repressivo, a partir do aparelhamento de instituições de vigilância e punitivas; e 4) intolerância social, a partir de dinâmicas voltadas para o compartilhamento de experiências individuais como parte das lógicas de personalização do consumo própria das redes sociais digitais. 
Em meio ao imbróglio sobre as disputas de informação científica, que implicam questões relacionadas a conflitos de interesses e apropriações de discursos científicos, três casos são abordados nessa pesquisa: o movimento antivacina, a Fosfoetanolamina e os supositórios Mineral Miracle Solution (MMS). Compreendemos que a ascensão do movimento antivacina é exemplo central do questionamento contemporâneo da medicina, exemplificando desconfiança de indivíduos comuns em relação às instituições científicas e constituindo uma das grandes preocupações mundiais ${ }^{21}$. Porém, o interesse dessa pesquisa não é olhar cenários globais, mas estudos de casos específicos de relevância nacional que implicassem na apropriação de discursos científicos para a propagação de uma informação que vai contra as próprias pesquisas científicas, a fim de que pudéssemos mapear as disputas de informação científica no Facebook e seus contextos políticos locais. Para além do movimento antivacina, os casos da pílula que cura câncer (Fosfoetanolamina ${ }^{22}$ ) e supositório que cura autismo (Mineral Miracle Solution ${ }^{23}$ ) emergiram na pauta midiática nos últimos anos, como exemplos de disputas políticas sobre a informação científica que representam a emergência das fake sciences funcionando como amplificador de discursos que propõem práticas anticientíficas como solução para problemas ainda não plenamente tratados pela medicina.

O movimento antivacina nasce dentro da própria academia e foi creditado ao pesquisador Andrew Wakefield ${ }^{24}$, que publicou na The Lancet ${ }^{i}$ uma pesquisa que associava a ocorrência de autismo à vacinação. $\mathrm{O}$ artigo sofreu duras críticas da comunidade acadêmica, sendo retratado na própria revista, e, após uma série de investigações do jornal britânico The Sunday Times, foi descoberto que algumas crianças voluntárias do estudo haviam sido indicadas por um escritório de advocacia sob a intenção de entrar com ações contra a indústria farmacêutica. Segundo pesquisa realizada por Anna Kata ${ }^{25}$, os argumentos antivacina relacionamse com temas como segurança e eficácia, medicina alternativa, liberdades civis, teorias da conspiração e moralidade. Ainda, de acordo com a autora ${ }^{26}$, as táticas utilizadas pelos defensores da antivacina implicam em distorção da ciência, mudança de hipóteses e ataques conjuntos aos defensores da vacinação. Para a autora, o movimento antivacina surge a partir de um novo paradigma pós-moderno de assistência médica, no qual há uma transferência de poder sobre a informação de médicos para pacientes, em que a legitimidade da ciência é questionada e a autoridade sobre a especialização é redefinida.

Da mesma forma que o movimento antivacina nasce dentro da comunidade acadêmico-científica, a substância fosfoetanolamina começou a ser produzida no laboratório do Grupo de Química Analítica e Tecnologia de Polímeros do Instituto de Química de São Carlos (IQSC-USP) ${ }^{i i}$ e distribuída no campus da universidade gratuitamente, sem consentimento da instituição. A polêmica ganhou forte repercussão nas redes sociais, a partir de relatos de supostas curas, junto com notícias de óbitos. Diante de uma crise jurídico-política que havia se instaurado no Brasil desde as manifestações de 2013, de acordo com Márcia de Cássia Cassimiro e colaboradores ${ }^{27}$, o movimento pela aprovação da distribuição da medicação foi visto como uma meta por muitos congressistas e parlamentares de diferentes partidos ${ }^{\mathrm{iii}}$, pressionando o governo pela aprovação de lei a fim de conseguir a simpatia de parte da população que sofre com câncer. Desconsiderando todos os procedimentos próprios da autorregulamentação científica, como testes préclínicos e clínicos exigidos na comprovação de qualidade, segurança e eficácia de medicamentos ${ }^{28}$, a Lei n. 13.269/2016 29 foi editada, autorizando o uso da substância por pacientes diagnosticados com neoplasia maligna, e juízes começaram a conceder liminares determinando o fornecimento da substância. Conforme

i Em 2010, o pesquisador teve sua licença cassada pelo Conselho Britânico de Medicina.

ii A fórmula está protegida sob as patentes PI 0800463-3 e PI 0800460-9.

iii PL 4639/2016, assinado por Adelmo Carneiro Leão - PT /MG; Arlindo Chinaglia - PT/SP; Carmen Zanotto - PPS/SC; Eduardo Bolsonaro - PSC/SP; Jair Bolsonaro - PP/RJ; Paulo Foletto - PSB/ES; Antônio Jácome - PMN/RN; Diego Garcia - PHS/PR; Conceição Sampaio - PP/AM; Dulce Miranda - PMDB/TO; Eduardo Barbosa - PSDB/MG; Miguel Lombardi - PR/SP; Zenaide Maia - PR/RN; Laura Carneiro - PMDB/RJ; Weliton Prado - PMB/MG; Professora Dorinha Seabra Rezende - DEM/TO; Flavio Nogueira PDT/PI; Celso Russomanno - PRB/SP. PL. Informação disponível em: https://www.camara.leg.br/proposicoesWeb/fichadetramitaca o?idProposicao $=2078864$ 
apontam Alves e $\mathrm{Bem}^{30}$, o procedimento jurídico desorganizou o sistema regulatório de saúde nacional ao rechaçar a legislação já consolidada desde a década de $1970^{31-33}$ sobre vigilância sanitária e registro de medicamentos. Após a Ação Direta de Inconstitucionalidade (ADI) n. 5501, movida pela Associação Médica Brasileira ${ }^{34}$, em 19 de maio de 2016, o Supremo Tribunal Federal suspendeu a lei que autorizava a distribuição da fosfoetanolamina ${ }^{35}$. Em 2018, a Procuradoria Geral da República se manifestou contra a comercialização da substância por trazer risco à saúde pública ${ }^{36}$, porém continua sendo comercializada como suplemento e com a promessa de cura até hoje em sites de redes sociais.

Ambos os casos, antivacina e fosfoetanolamina, apontam para conflitos éticos de interesses científicos, que envolvem a indústria farmacêutica, o governo e a mídia, instituições vistas com desconfiança pelos adeptos de teorias da conspiração ${ }^{7,37}$. De acordo com pesquisa em que se analisaram páginas antivacinação australianas no Facebook, os discursos identificados concentravam-se em indignação moral e opressão estrutural por parte do governo institucional e da mídia, sugerindo uma forte lógica de crenças e de teorias de conspiração $0^{38}$, fruto de uma crise epistêmica sobre as instituições legitimadas como produtoras de conhecimento. Constantemente associada à desinformação e ao excesso informacional ${ }^{39}$ e a uma agenda conservadora religiosa de direita ${ }^{40-41}$, esta crise epistêmica é o reflexo de um regime regulado pela crença individual e pela experiência pessoal $4^{2}$ e uma desconfiança generalizada nas instituições basilares da democracia, muito em função da própria midiatização de controvérsias ${ }^{43} \mathrm{e}$ dos próprios conflitos de interesses entre esses atores. Neste cenário, emergem movimentos conspiratórios em que a informação é um campo de disputa sobre a produção de narrativa.

É no seio desses espaços de circulação de teorias da conspiração, e não no campo científico, como no caso da antivacina e da fosfoetanolamina, que surge a polêmica sobre o uso do supositório MMS - sigla de Mineral Miracle Solution - para a cura de autismo. O MMS é um dióxido de cloro utilizado nas indústrias de papel a fim de clarear a polpa da madeira, de alto nível tóxico. Inicialmente propagado a partir dos trabalhos do bispo Jim Humble, autor de A Solução Mineral Mestre do $3^{\circ}$ Milênio, publicado em 201144, o MMS tem se espalhado por diversos países, sobretudo após a criação da Genesis II Church of Health and Healing, fundada pelo próprio bispo e com mais de 300 ministérios, segundo informa o site ${ }^{45}$.

Conforme relata Werner ${ }^{46}$, $\mathrm{MMS}$ se tornou conhecido depois da publicação do livro Curando sintomas conhecidos como autismo, da homeopata norte-americana Kerri Rivera, publicado em 2016 pela editora BvBooks, e divulgado em veículos de grande circulação, como a Revista Exame ${ }^{47}$. Em seu livro, a autora descreve procedimentos de introdução do produto diluído diretamente no intestino da criança, por via anal - os supositórios de MMS. Segundo relata a homeopata, o uso da substância provoca a descamação das paredes do intestino e libera um tipo de muco, que é apontado pela autora e outros defensores da prática como vermes causadores do autismo. Para além de promessa de cura de malária e autismo, tem sido recorrente a indicação do MMS para tratamento de doenças diversas em animais domésticos.

Estudos apontaram os perigos do uso da solução ${ }^{48,49}$, inclusive a US Food and Drug Administration. No entanto, a circulação desse tipo de desinformação continua sendo realizada em espaços digitais. Recentemente, ela tem ganhado adeptos como Dr. Lair Ribeiro, que defende publicamente o uso da substância, alegando que sua proibição tem relação com interesses de grandes empresas contrariadas com a venda de "um negócio que cura tudo, sem efeito colateral e a preço de banana" ${ }^{\circ}$. Dr. Lair Ribeiro é um médico com passagem pela Harvard Medical School, mais famoso por ser escritor de best-sellers de autoajuda. Ele defende abertamente o uso do MMS, com vídeos propagando a substância compartilhados em páginas fake science, que evocam sua autoridade científica como fator legitimador dos argumentos.

A circulação de fake sciences tem sido motivo de preocupação de diversos setores, inclusive as próprias plataformas digitais, diante do enfrentamento de críticas da sociedade sobre a responsabilidade dessas empresas em dar visibilidade às desinformações científicas. Segundo informado pelo CanalTech ${ }^{51}$ em julho de 2019, o Facebook anunciou que iria rebaixar postagens que contivessem afirmações não oficiais sobre 
a saúde, ou mesmo anúncios e publicações que trouxessem promessas de cura ou milagre relacionados ao tratamento de doenças, entre eles o MMS, o que tem levado a uma série de discussões sobre controle e formas algorítmicas de censura on-line, incluindo a extensa vigilância de comunicações e o uso de sistemas de aprendizado de máquina com a possibilidade distinta de erros e preconceitos.

\section{Controle e desinformação em redes sociais}

Estudos anteriores nos EUA ${ }^{52}$, Europa ${ }^{53}$ e Brasil ${ }^{54}$ revelaram que as mídias sociais se tornaram uma importante fonte de notícias e informações para o público, mais do que o jornalismo tradicional, que tem sido entendido como um dos meios pouco confiáveis devido a um histórico de posicionamentos políticos que se afastavam do modelo ocidental anglo-americano de objetividade e imparcialidade ${ }^{18}$. Tal como a ciência, o jornalismo - e a mídia massiva como uma das instituições das comunidades epistêmicas - baseado em valores e normas próprias consensuadas entre a comunidade, tornou-se progressivamente distintivo da sociedade. Segundo aponta Camila Tavares ${ }^{55}$, os valores distintivos no qual o jornalismo fora consolidado o afastaram da esfera política, mas, por outro lado, acabou se tornando dependente da esfera econômica, tornando-o vulnerável a fluxos econômicos.

Segundo aponta Nielsen ${ }^{56}$, para além de crises financeiras do jornalismo, há uma crise de confiança pública, potencializada pelo desenvolvimento de tecnologias da comunicação e informação, sobretudo os sites de redes sociais digitais. A partir de uma lógica de mercado neoliberal ${ }^{57}$ voltada para a personalização de consumo informacional, essas plataformas de redes sociais digitais têm se tornado um espaço primordial para a informação - e desinformação - na atualidade, visto que $57 \%$ dos brasileiros que mantêm contas ativas no Facebook informam-se pela plataforma, de acordo com o relatório publicado em 2018 pela Digital News Report 53 .

Embora haja uma ocorrência desde muito antes da Internet ${ }^{58}$, a desinformação é amplificada com a ascensão das mídias sociais uma vez que nestes espaços autoridades tradicionais sobre a informação convencional médica, como jornalistas e especialistas, têm um alcance limitado ${ }^{59}$, contando com uma forte concorrência de canais informais pela competência destes conhecimentos. Isso tem resultado em uma fácil exposição de grande parte dos usuários de redes sociais a conteúdos que promovem desconfiança em instituições médicas, teorias da conspiração e narrativas pessoais pautadas em discursos anticientíficos ${ }^{60}$.

Essa desconfiança sobre as intenções de instituições tem se intensificado desde a segunda metade do século XX, quando uma série de crises públicas no ocidente envolvendo, por exemplo, escândalos públicos estadunidenses como o Watergate, a Guerra do Vietnam e o assassinato de JFK, e a instauração de ditaduras na América Latina por meio de violentos golpes de estado, expuseram fragilidades de governos e democracias. Quanto à mídia, tem-se observado um aumento da dependência dos meios de comunicação ${ }^{61}$ em relação aos setores econômicos, cada vez mais alinhados com o lucro, engajando-se em reportagens sensacionalistas e duvidosas ${ }^{62}$. Já em relação às instituições científicas, as crises estão relacionadas à incapacidade da ciência em tratar de problemas sociais ${ }^{10}$, com a academia cada vez mais afastada de seu propósito de bem comum à sociedade para atender às demandas da esfera econômica, como vem discutindo Signates ${ }^{63}$. Para além da incapacidade da ciência de cumprir as promessas da modernidade de resolver as mazelas sociais, as mensagens dissonantes da própria ciência e as disputas epistemológicas dentro do campo científico percebido pelo público impulsionam sentimentos de desconfiança sobre as informações relacionadas à ciência ${ }^{64}$. Junto a esses fatores, o declínio de confiança sobre a ciência tem sido observado ao longo das décadas, sobretudo em função de uma percepção sobre conflitos de interesses e politização da ciência ${ }^{6}$.

Esta crise de credibilidade de instituições legitimadas como produtoras de verdade - como a ciência e a mídia - aliada ao espaço de circulação de informações disponível na Internet para novos agentes dá 
visibilidade a pensamentos não-validados que sempre existiram, mas outrora não possuíam tal alcance, como as teorias da conspiração, o terraplanismo e o próprio movimento antivacina.

Inúmeros têm sido os trabalhos que buscam entender o fenômeno das fake new ${ }^{66-70}$. Estes estudos, na maior parte das vezes, pautam-se pela preocupação com a ameaça que as fake news representariam para a autoridadejornalística idealizada e não costumam avançar em relação às implicações sociais desta ferramenta política. Por exemplo, quando os fake news são replicadas por agentes representativos do governo e por movimentos políticos extremistas, autoridades e pessoas públicas ${ }^{71}$, como o presidente dos Estados Unidos, Donald Trump, usando as próprias redes sociais para questionar a vacinaçãa ${ }^{72}$; o autoproclamado filósofo Olavo de Carvalho repetindo a atitude ${ }^{73}$, e o recente corte de 500 milhões do programa de imunização feito pelo presidente do Brasil, Jair Bolsonaro ${ }^{74}$, é preciso abordar o tema com cautela para o enfrentamento da desinformação. Nesse sentido, duas vertentes recorrentes desse enfrentamento emergem nesse cenário: as ações de controle sobre a informação e as ações de campanhas pró-informação.

As ações de controle e classificação normativa sobre a veracidade da informação emergem tanto no cenário do jornalismo, quanto no da ciência. Agências regulatórias baseadas em definições de verdade pela verificabilidade propõem medidas de controle, sobretudo para aqueles veículos comprometidos com a promoção de perspectivas diferentes da mídia tradicional ${ }^{18}$, no caso do jornalismo, e para aquelas vertentes epistemológicas que se diferem dos princípios da ciência moderna - como no caso de tratamentos alternativos de saúde.

No campo do jornalismo, o modelo de checagem da veracidade dos fatos dos veículos de informação tradicionais busca quebrar com a lógica neoliberal descentralizada da produção de conteúdo em mídias sociais ${ }^{5}$, retomando discursivamente a importância da mídia massiva como ator de confiança em um cenário de circulação de desinformação. Por sua vez, as ações pautadas em campanhas pró-informação partem de um modelo linear da comunicação, ignorando as lógicas próprias das redes sociais digitais, por onde seu conteúdo circula ${ }^{75}$, mais do que o próprio movimento antivacina, por exemplo ${ }^{76}$. A lógica de big data e todas as dinâmicas derivadas dos avanços tecnológicos em torno da algoritmização pela experiência do usuário, próprios do sistema neoliberal do consumo personalizado de informação, têm permitido que a informação e a desinformação avancem a partir de escolhas, hábitos e preferência de consumo de usuários. Estamos nos isolando em "bolhas informacionais" e "câmaras de ecos"77), metáforas utilizadas para compreender o fluxo informativo limitado a grupos coesos, sem acesso a um amplo espectro da informação que vá de encontro às visões de mundo do usuário. Além disso, outras dinâmicas próprias desses espaços digitais são ignoradas, como páginas controladas por bots no Twitter, canais não-destacados no YouTube, grupos fechados no WhatsApp, entre outros.

Recentemente, a plataforma de vídeos YouTube declarou esforços em cercear o conteúdo extremista ${ }^{78} \mathrm{e}$ desinformativo, limitando o alcance, a monetização ou atémesmo deletando-o. Entretanto, é difícil identificar efetividade nessas políticas, com outras redes como Facebook e Twitter também limitando a visibilidade de tais conteúdos, mas mantendo-os públicos ${ }^{79}$, deixando o conteúdo vivo para o compartilhamento, sob a égide discursiva de democracia e liberdade de expressão. Mark Zuckenberg, fundador do Facebook, em um esforço contra a antivacinação, compartilhou em sua rede social uma foto levando sua filha ${ }^{80}$ para a vacinação; a postagem recebeu uma chuva de comentários antivacinação. Em entrevista para a revista Forbes sobre o tema, Zuckenberg respondeu: "Se alguém quiser postar um conteúdo antivacina, ou entrar em um grupo com essa discussão, não os impedimos de fazer isso. Mas tentamos fazer que o nosso sistema de recomendação não encoraja ninguém a entrar nestes grupos. [...] Nos importamos profundamente em dar às pessoas uma voz, uma liberdade de expressão"

A citação evidencia um posicionamento complexo das gigantes plataformas de redes sociais sobre a desinformação: enquanto a postura pública é admitir o problema e tentar timidamente endereçá-lo, as políticas capitalizadas posicionam as empresas numa forte não-intervenção, que efetivamente faz do espaço 
digital um ambiente permissivo e desregulado, propício para o discurso persuasivo, emotivo e populista que emergem no cenário de disputa de informação.

\section{Mapeamento no Facebook}

A Internet é um importante espaço de busca de informações ${ }^{82-83} \mathrm{e}$ tem tido um papel significativo na formação de comportamentos em saúde ${ }^{84-85}$. No contexto das mídias sociais, o Facebook tem sido considerada uma plataforma relevante nesse cenário para buscas e compartilhamento de conteúdo relacionado à saúde, principalmente devido à sua natureza interativa que facilita a troca de apoio social ${ }^{86}$, com grande capacidade de influenciar o discurso público sobre saúde de maneira viral, tanto positiva quanto negativamente ${ }^{87}$. Diante disso, esta pesquisa busca levantar páginas brasileiras e grupos de Facebook que possam ser potenciais espaços de disseminação de desinformação sobre os tópicos contemplados por esta investigação. Por meio de uma pesquisa qualitativa de observação não-participante ${ }^{88}$, análise de conteúdo ${ }^{89} \mathrm{e}$ a partir de técnicas de snowballing de recomendação algorítmica ${ }^{90}$, foram identificadas páginas com maior número de seguidores e grupos com maior número de inscritos de cada um dos tópicos desta pesquisa: antivacina, fosfoetanolamina e MMS.

A busca sobre antivacina nos retornou apenas um resultado de página e um resultado de grupo em português, podendo indicar um esforço do Facebook em excluir perfis e espaços que compartilhem informações contra vacinação. Já a busca por fosfoetanolamina teve um retorno de 74 páginas e 96 grupos, enquanto a busca por MMS (e combinações com sódio e autismo) teve um retorno de 18 páginas latino e ibero-americanas, sendo apenas duas brasileiras (Mms - solução mineral milagrosa, com 441 curtidas e Movimento MMS Brasil, com 400 curtidas), as únicas utilizadas em nosso corpus de análise. Convém ressaltar que, como as palavras-chaves utilizadas (MMS OR solução mineral milagrosa OR Mineral Miracle Solution) nos retornaram uma busca para além da utilização do termo em português, nossa coleta se deparou com resultados advindos de outros países, que foram excluídos da nossa amostra para análise. Os países relacionados à busca sobre MMS no Facebook e que foram demarcados sobre a localidade em seus títulos são: Argentina, Brasil, Bolívia, Chile, Costa Rica, Espanha, Guatemala, México e Peru. Além disso, também foram identificados seis grupos de Facebook sobre o tema, também com demarcações de localidades evidentes em torno de cidades como Arica e Santiago no Chile e Monterrey, no México. Uma das possíveis leituras sobre essas demarcações de localidades reside na própria atuação midiática desses países na midiatização da cura milagrosa. No Chile, o MMS foi amplamente divulgado pelo Canal 13, no programa Bienvenidos, pelo Dr. Ricardo Soto, médico integrativo e diretor do instituto Medicina Consciente, que tinha um quadro na TV aberta sobre tratamentos alternativos. Após o ocorrido, o médico foi afastado da televisão pela Seremi de Salud Metropolitana. Contudo, outros médicos e autoproclamados agentes de saúde permanecem em outros canais da televisão aberta e no YouTube propagando a venda do suplemento amplamente nesses espaços e em seminários voltados para o tema ${ }^{91}$. Já o México abriga o cientologista Jim Humble, principal difusor do MMS no mundo, que devido a perseguições e acusações foi obrigado a sair dos Estados Unidos e refugiar-se no país, onde a comercialização da substância é livre. Ainda que o tema não seja de grande repercussão nos sites de redes sociais, essas demarcações de localidades indicam a formação de redes de interesse na América Latina, abrindo para possibilidades de investigações futuras a partir de contextos locais. 
Tabela 1 - Resultado quantitativo do mapeamento no Facebook

\begin{tabular}{lcc} 
Buscas & n. de páginas & n. de grupos \\
Antivacina & 1 & 1 \\
Fosfoetanolamina & 74 & 96 \\
MMS & 2 & 0 \\
\hline
\end{tabular}

Fonte: Dados da pesquisa (2019).

Nota: n.= número. Quadro com informações de retorno por meio de busca no Facebook.

\section{Recomendação algorítmica}

Para uma classificação do tipo de página derivada da recomendação algorítmica, e baseado nas discussões previamente apresentadas, é possível analisar os materiais coletados a partir das seguintes questões: 1) os elementos de autoridade científica e as apropriações de discursos científicos que emergem no fenômeno entendido como fake sciences (7), baseado na imitação de signos científicos como estratégia de convencimento. Tais estratégias têm sido adotadas para a 2) comercialização de produtos e serviços para o bem-estar e a saúde, vendidos como curas milagrosas e terapias alternativas, buscando preencher lacunas não desvendadas pela ciência. Esses produtos milagrosos refletem um anseio da população não apenas na crença de soluções para demandas sociais não atendidas pela ciência, como também apontam para uma descrença institucional na qual os conflitos de interesse sobre as indústrias farmacêuticas e as instituições de pesquisa são criticados pela sociedade. 3) Dentre as prestações de serviços, vetores jurídicos ascendem em prol dos direitos do cidadão, sobretudo pelo direito à informação e acesso a esses tratamentos alternativos.

4) Para além do caráter de mercantilização de dogmas e crenças na oferta de produtos e serviços, as lógicas de busca por reputação nos espaços sociais digitais permitem surgir não apenas os prestadores de serviços, mas também ativistas e advocacy, como práticas políticas de indivíduos ou organizações, no interior das instituições do sistema político, com a finalidade de influenciar a formulação de políticas e a alocação de recursos públicos. 5) A partir da quebra de confiança nessas instituições epistêmicas que balizam noções como verdade, os sujeitos passam a acreditar apenas em suas próprias experiências individuais, nesses sujeitos cuja reputação nos espaços digitais os levam a exercer algum tipo de influência na esfera pública e econômica, e o discurso do testemunho passa a ter grande valor na sociedade como parte das lógicas de personalização do consumo própria das redes sociais digitais e parte de formas contemporâneas de relação da cultura da crença baseada no self.

Mediante essas definições de lógicas e dinâmicas que estão implicadas na circulação da informação científica em sites de redes sociais, a partir das páginas coletadas inicialmente no mapeamento, foi realizado um levantamento das recomendações do algoritmo para páginas relacionadas, traçando uma rede para a identificação dos atores de influência.

A partir da única página brasileira identificada na busca inicial sobre o movimento antivacina (O lado obscuro das vacinas ${ }^{91}$ ), foi possível mapear nove páginas relacionadas de primeiro nível, indicadas pelo algoritmo do Facebook, que podem ser agrupadas nos seguintes temas:

- Autoridade científica e tratamentos alternativos $(\mathrm{n}=5)$ - Médicos que Ensinam a Prevenir Doenças, Criação Neurocompatível por Márcia Tosin, Admiradores Do Professor Afonso De Vasconcelos Lopes, Naturopata Rc e Coletividade Evolutiva;

- Política, Conservadorismo e valoração da família (n=4) - Brasil Sem Aborto, Nunca Houve Ditadura Militar No Brasil e RED ALERT Almagesto; Tisquinho de Gente. 
Como a busca sobre Fosfoetanolamina retornou um resultado de 74 páginas, foram selecionadas as seis páginas com maior número de curtidas para a identificação de recomendações algorítmicas sobre o tema. Para tanto, foram selecionadas as seguintes páginas: Fosfoetanolamina Testimonials ${ }^{93}$ (44.972 curtidas); Fosfoetanolamina $^{94}$ (32.566 curtidas); Fosfoetanolamina A Esperança Proibida ${ }^{95}$ /(19.862 curtidas); Fosfoetanolamina Oficial ${ }^{96}$ (13.976 curtidas), Fosfoetanolamina Sintética Goiás ${ }^{97}$ (6.487 curtidas) e Fosfoetanolamina Sintética - Pela continuidade da pesquisa contra o câncer ${ }^{98}$ (4.734 curtidas).

Foram identificadas 35 páginas, agrupadas nos seguintes temas:

- Autoridade científica e tratamentos alternativos (n=14) - Fosfoetalonamina, Pílula Contra O Câncer; Fosfoetanolamina Sintética, Fosfoetalonamina; Dr Renato Meneguelo; Fosfoetanolamina, Fosfo a cura proibida, Suplementos e Fosfoetanolamina, Fosfoetanolamina Sintética Goiás, Phospho Ethanolamine - Brasil, Alcool Perilico na luta contra tumor cerebral, Fosfoetanolamina sintética - a cura, Ozônio Terapias Complementares, Rosane Cincinatus Nutricionista, Entendendo a dependência química;

- Prestação de serviços jurídicos e previdenciários (n=9): Fábio Motta - Advogado Imobiliário, Notarial e Registral, BRS Explica, Oratória Jurídica, Servidores de Conselhos de Classe, Guilherme Portanova / Assessoria, Abreu Advocacia, Escola de Previdenciaristas, Dindin Finanças Pessoais;

- Ativismo ( $\mathrm{n}=5)$ - Fosfoetanolamina Sintética - Para Todos, Chris Morais Ativista Fosfoetanolamina, Eu Apoio a Liberação da Fosfoetanolamina, Diego Rodriguez e Rosangela da Silva;

- Comércio de Saúde e bem-estar ( $\mathrm{n=5}$ ) - Viva Vida, Revista Bem Viver, Rede de Viveiros de Mudas Nativas do Vale, Revista Viver Saúde e Geradores de Ozônio;

- Política, Conservadorismo e valoração da família $(\mathrm{n}=2)$ - Primeira Igreja Batista Maná Renovada, Inteligência Emocional para Pais.

Observando as duas páginas identificadas no mapeamento no Facebook sobre MMS (Mms - solução mineral milagrosa ${ }^{99}$, com 441 curtidas e Movimento MMS Brasil, com 400 curtidas), foi possível coletar 19 páginas relacionadas indicadas pelo algoritmo do Facebook, agrupadas sobre os seguintes temas:

- Autoridade científica e tratamento alternativos ( $\mathrm{n}=11)$ - Andreas Kalcker in RIO, Prata coloidal, A Cura Proibida mms, EU USO ORMUS e GANS, Caneta da saúde, plasma magrav, Gans \& Ormus Brasil, Maria Helena Rossi Homeopata, Fazendo Ozonioterapia, Oxygen Therapy, MMS;

- Comércio de Saúde e Bem -estar (n=4) - Geradores de Ozônio, Geradores de Ozônio OZOXI, Beleza e Ozonoterapia, OzonAr- Equipamentos para o Meio Ambiente;

- Ativismo (n=2) - ONG Bem Estar Animal e ONG Proteção Animal Brasil;

- Política, Conservadorismo e valoração da família (n=2) - MpuForteServidorValorizado e Breno vereador 2020. 


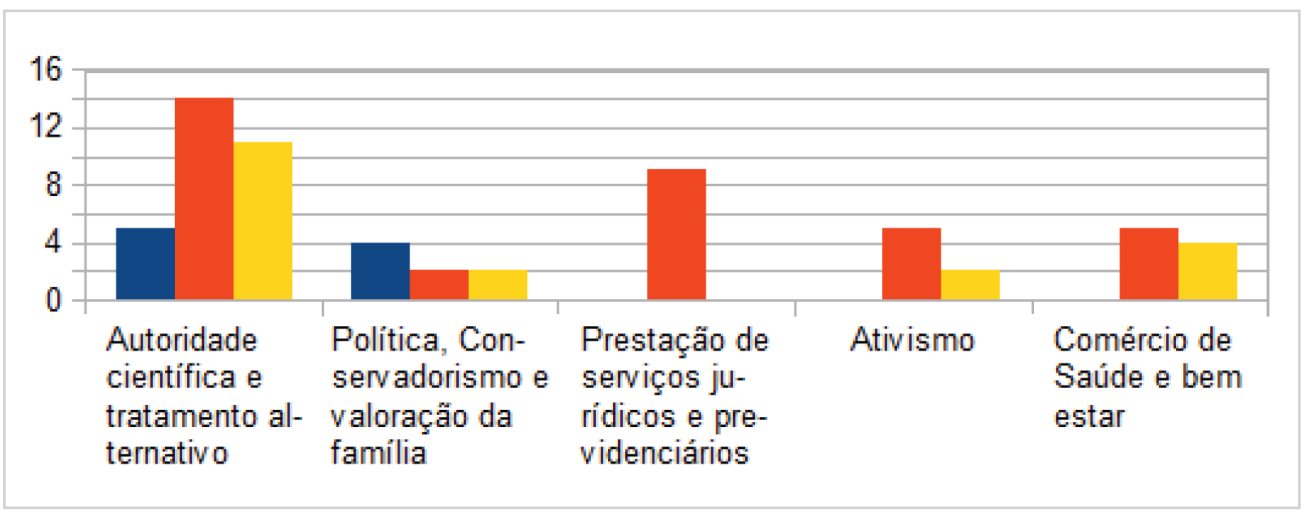

Figura 1 - Temática encontrada em cada categoria analisada

Fonte: Dados da pesquisa (2019).

\section{Tipos de conteúdo, interações sociais e atores de influência}

Na página identificada como parte do movimento antivacina é recorrente o uso de argumentos lógicos e uso de artigos científicos para refutar ideias. Alguns dos periódicos mencionados são considerados de prestígio no campo científico, indexados no Pubmed ou parte do acervo de empresas editoriais científicas como Springer-Nature. Constantemente são publicados vídeos do YouTube com cientistas vestidos de jalecos, demarcando suas performances condicionadas à atuação profissional.

Já as interações apontam para um discurso contra mídia e contra a ciência, sobretudo acionando discursos sobre conflitos de interesses, como por exemplo, nos casos abaixo que ilustram a desconfiança dos sujeitos em relação não só às instituições e associações científicas e a mídia (Figura 2), mas também aos próprios mecanismos de controle das agências de checagem de fatos.
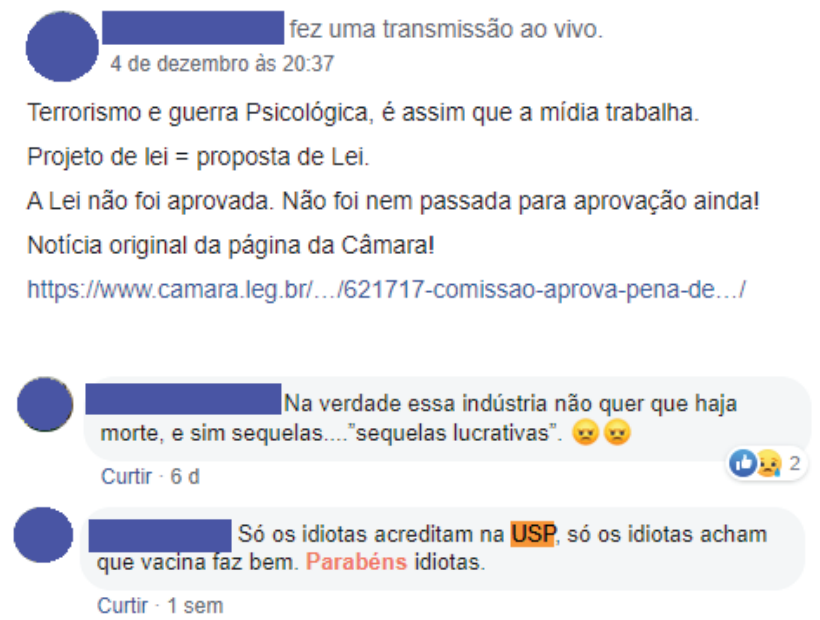

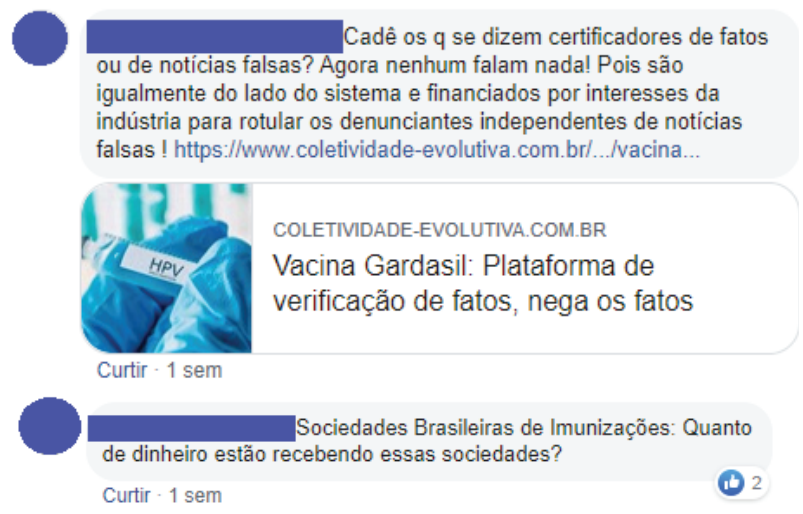
Curtir - 1 sem

Figura 2 - Comentários postados na página O lado obscuro das vacinas Fonte: Dados da pesquisa (2019)iv.

Dentre as 35 páginas identificadas na coleta sobre Fosfoetanolamina, foi gerado um grafo em Gephi, buscando identificar os nós de influência a partir do grau de entrada dos 41 nós e 83 arestas reconhecidos. Destaca-se que a recomendação algorítmica para quatro $(n=04)$ páginas que se encontram como nó de influência a partir do procedimento aplicado, conforme é observado na Figura 3.

iv Tais comentários são apenas ilustrativos, nos fornecendo insumos para desdobramento de pesquisas futuras, a partir de recortes temporais e metodologias próprias para a análise de conteúdo e dinâmicas interacionais nesses espaços. 


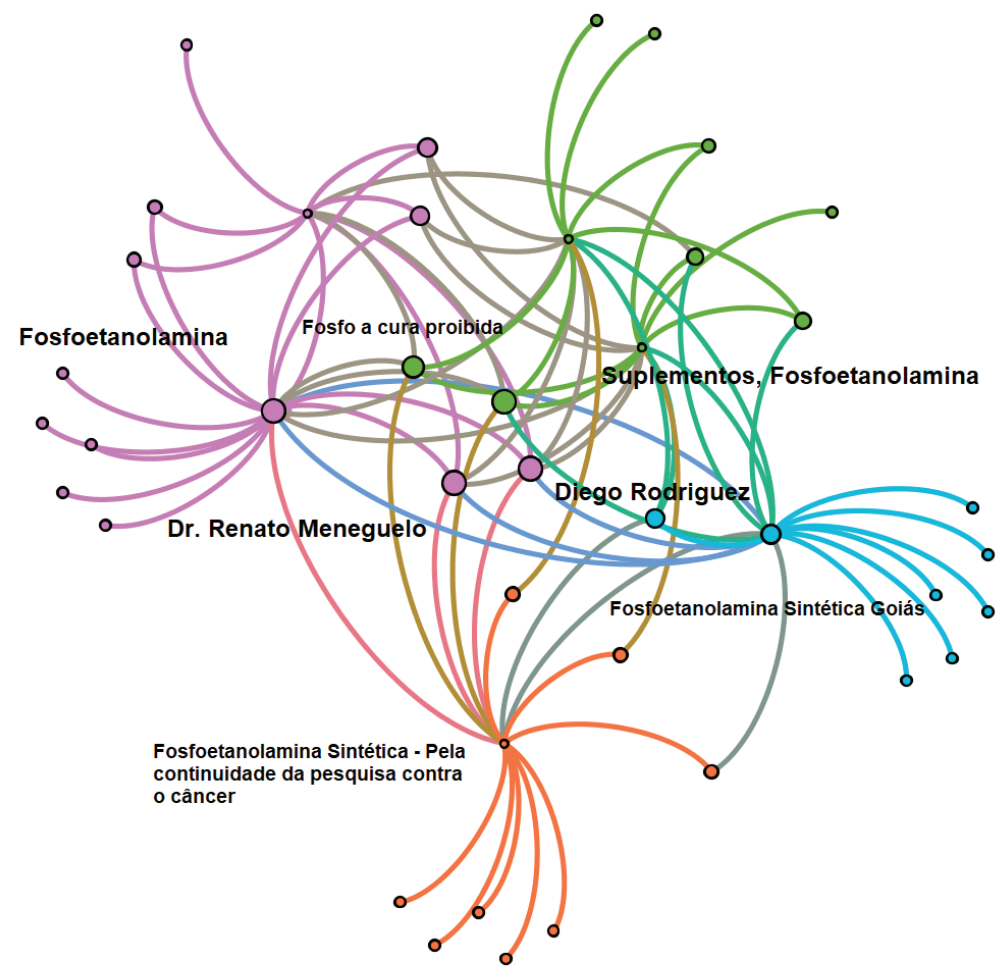

Figura 3 - Gráfico de recomendações algorítmicas Fonte: Dados da pesquisa (2019).

Os nós de maior influência são:

1. Suplementos, Fosfoetanolamina e Tratamentos Alternativos - Instituto ${ }^{100}$, página do Instituto É seu direito saber ${ }^{101}$, de Renato Meneguelo que atualmente possui 7.400 curtidas, e que tem como propósito divulgar temas relacionados a tratamentos alternativos a partir de discursos científicos. Como é apontado na capa da página, a questão de direito à informação é latente a partir dos dizeres 'É seu direito saber', que leva o nome do instituto. Os temas publicados neste espaço relacionam-se aà informações científicas sobre doenças como fibromialgia, indicações de tratamentos alternativos como biomagnetismo e óleos essenciais, além de acompanhamento de etapas jurídicas sobre as ações de fosfoetanolamina;

2. Fosfoetanolamina ${ }^{102}$, página com 4.346 curtidas que se descreve como um espaço voltado para divulgação de Ações Judiciais para a obtenção ao direito de o paciente de câncer ter acesso ao uso da substância fosfoetanolamina sintética desenvolvida pela USP. Dentre as publicações, o post fixo indica um propósito claro: venda de suplemento PhosphoEthanolamine, produzido pela Quality Elements. Para além disso, tem servido como um espaço de divulgação científica de membros do grupo da Unicamp que desenvolveu pesquisas sobre a substância, além de utilizar vídeos postados no YouTube e depoimentos de testemunhos como estratégia de divulgação do tratamento;

3. Dr. Renato Meneguelo ${ }^{103}$, com 11.809 curtidas, membro restante do grupo da Unicamp que desenvolveu pesquisas sobre a substância e continua atuante no ativismo sobre o uso da fosfoetanolamina junto à esfera política, com publicação sobre encontros com membros congressistas e parlamentares que defenderam o movimento pela aprovação da distribuição da medicação em 2016. Nesta página, o discurso de cientificidade é mais evidente pela própria formação de Renato Meneguelo na área da saúde (Medicina) e mestrado em Bioengenharia ${ }^{104}$; 
4. Diego Rodriguez ${ }^{105}$, página com 7.185 curtidas, que tem como proposta, em sua descrição, "lutar contra a Indústria do CÂNCER. Indústria mais lucrativa do planeta”, expondo "o andamento dos testes da substância fosfoetanolamina sintética (síntese Dr. Gilberto Chierice- USP) e todas as falcatruas”. Nesta página são recorrentes postagens de denúncia à indústria farmacêutica e celebração aos congressistas, sobretudo ao atual presidente Jair Bolsonaro, pelo apoio à causa.

Destacam-se ainda duas páginas, que exercem influência dentro de suas redes. Fosfoetanolamina Sintética Goiás, com uma atuação política forte, apresentando conteúdos sobre CPI da Pílula do Câncer, que apontou falhas na condução dos testes clínicos realizados pelo ICESP (Instituto do Câncer de São Paulo) para checar a segurança e a eficácia do remédio no tratamento do câncer ${ }^{106}$ a se apresentar como "finalidade única promover a continuidade da pesquisa da Fosfoetanolamina, substância sintética, desenvolvida pela USP em São Carlos - SP". Com diversos links ${ }^{107}$ direcionando para o YouTube, há uma predominância de discurso jurídico com Jeff Vaz (Anjo Negro), advogado especialista em direito da saúde (fosfoetanolamina), e direito criminal.

Já nas páginas observadas sobre MMS, o tipo de conteúdo produzido é baseado em tutoriais e receitas para preparação da substância de maneira caseira (Figura 4). Por sua vez, as interações refletem a polarização sobre o tema. Por um lado, um conjunto de adeptos da substância reflete o descrédito da mídia e das instituições científicas. Por outro lado, outros sujeitos recorrem às instituições regulatórias ou produtoras de conhecimento, próprias das comunidades epistêmicas, como é o caso da Polícia Federal, Anvisa, Dr. Drauzio Varella e Globo News, além de influenciadores digitais como a página Lagarta Vira Pupa, marcando-os nas publicações na esperança de que estas instituições derrubem a página (Figura 5).

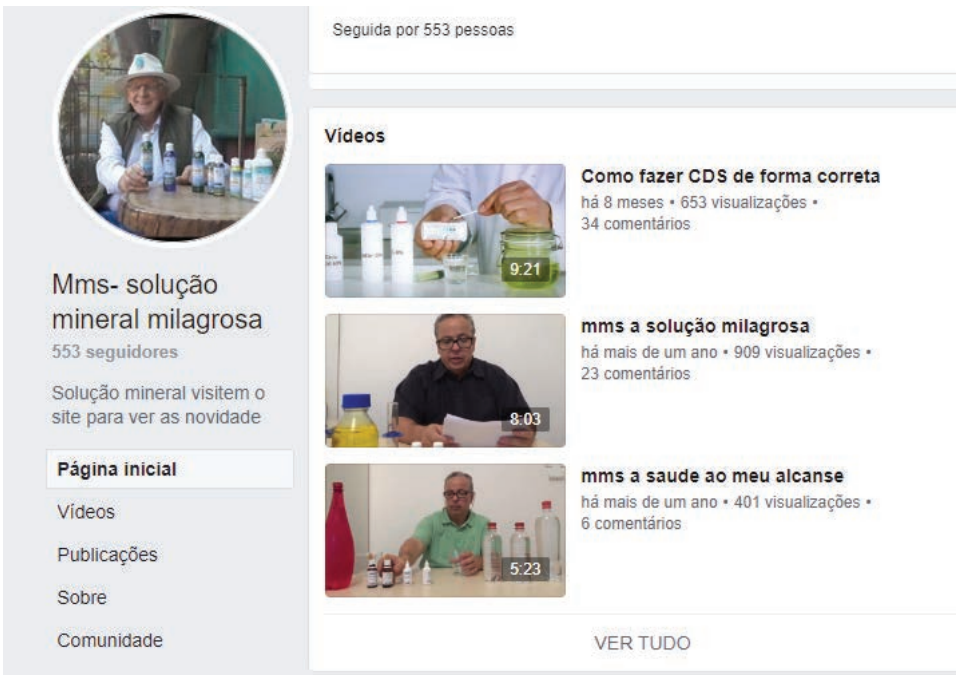

Figura 4 - Vídeos tutoriais da página Mms- solução mineral milagrosa Fonte: Mms- solução mineral milagrosa (2019).

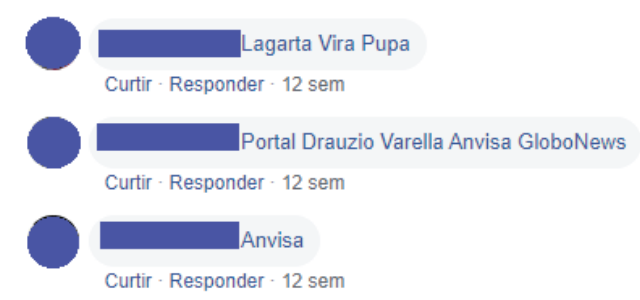

Figura 5 - Comentários extraídos da página Mms- solução mineral milagrosa Fonte: Dados da pesquisa (2019). 


\section{Discussão}

A triangulação derivada do exercício de abordagem multimétodos nos permitiu inferir que as fake sciences ocupam um campo de disputa no qual a autoridade científica é um valor relevante nesses espaços, sendo recorrentemente acionado como signo de convencimento junto ao público. Em todas as páginas analisadas e procedimentos realizados nesta pesquisa mista, algumas observações nos levam a entender que a algoritmização pela experiência tem permitido que a informação e a desinformação avancem a partir de escolhas, hábitos e preferência de consumo de usuários. As bolhas informacionais são reforçadas pelos algoritmos de personalização por meio da recomendação de páginas relacionadas. Contudo, apesar de ser uma metáfora poderosa para compreender o fluxo informativo limitado a grupos coesos, sem acesso a um amplo espectro da informação que vá de encontro às visões de mundo do usuário, tais canais ainda são usados, mesmo que timidamente, como espaço de embates entre ideias.

Nesses espaços interacionais, observam-se discursos de descrença institucional que fica manifesta nos comentários. Os sujeitos demonstram não confiar nem na ciência, nem na mídia. Apesar disso, acionam elementos próprios de signos científicos, como jalecos, textos acadêmicos publicados em espaços de prestígio e reforço pela titulação de quem produz conteúdo, como uma forma de validar seus argumentos. Por sua vez, as notícias que circulam nesses espaços variam entre a mídia tradicional massiva, que publica as controvérsias científicas sobre esses temas e os imbróglios econômicos, políticos e jurídicos derivados de disputas sobre o desenvolvimento de medicação de um lado, e entre vídeos caseiros de testemunho de cura e de receitas para a manipulação das substâncias em casa, sob um discurso de democratização da informação relacionada à saúde.

Assim, os resultados desta pesquisa apontam que as fake sciences são um campo de disputa intermediada de interesses econômicos e comerciais, políticos ejurídicos nos quais a informação e a descrença institucional derivada da crise epistêmica são o eixo central dos embates. De um lado, os avanços científicos, como já apontava Thomas $\mathrm{Kuhn}^{108}$, se dão a partir de longos embates dentro do próprio campo científico em um sistema autorregulado pelos próprios cientistas cada vez mais dependentes da midiatização da ciência para a obtenção dos escassos recursos financeiros. Esses embates e controvérsias naturais próprios da ciência são constantemente midiatizados, influenciando no declínio da confiança da população pela ciência. Por sua vez, a sociedade, cada vez mais descrente nas instituições produtoras de conhecimento, passa a buscar saídas em torno da crença em soluções rápidas e alternativas para temas que a ciência da saúde ainda está se desdobrando para entender, fazendo emergir fenômenos como as fake sciences.

Dessa ânsia por resultados rápidos, combinada à midiatização de controvérsias na ciência, as discussões acerca do direito à informação e acesso a esses tratamentos alternativos são acionadas como discursos baseados em argumentos jurídicos, que reforçam a complexidade do fenômeno referente à disputa pela informação científica e, consequentemente, a um sistema de reputação na busca por interseção na formulação de políticas desses atores. Nesse sistema de reputação em ambientes digitais, o testemunho é um tipo de produção de narrativa recorrente entre esses sujeitos, um tipo de linguagem apreciada por aqueles que, descrentes das instituições, valorizam as narrativas pessoais.

Por sua vez, as recomendações algorítmicas exercem uma conexão relevante na influência em redes sociais digitais. Tais recomendações tendem a reduzir o contato com visões divergentes, crucial para o fortalecimento do debate, restringindo caminhos de usuários e limitando os vieses de confirmação de sujeitos que estão em busca da cura para si ou de seus familiares. Se as instituições consideradas produtoras de verdade se encontram em crise devido a seus próprios conflitos de interesses com entrada de outros atores no desenvolvimento da pesquisa, como atores políticos e econômicos, os sujeitos passam a acreditar apenas em suas experiências pessoais e buscam informação em seus próprios fluxos informacionais conduzidos por recomendações algorítmicas. 
Em um momento em que o conservadorismo tem sido observado tanto na esfera política e social, os valores morais reguladores de nucleação tradicional se encontram com as lógicas neoliberais sobre os indivíduos, voltadas para um consumo personalizado próprio das redes sociais digitais como parte de formas contemporâneas de crença baseada no self. Esta dinâmica social baseada em seus consumos e crenças individuais gera intolerância para informações divergentes, princípio necessário para a ordem democrática sobre a informação.

\section{Considerações finais}

Buscamos neste artigo mapear espaços responsáveis pela circulação de teorias da conspiração pseudocientíficas, recentemente referidas como fake sciences. Fake sciences são tradicionalmente repudiadas no campo acadêmico, sendo pouco estudadas seja pela sua estranheza, por violar agressivamente o cânone científico ou mesmo pelos seus comprovadamente perigosos efeitos na sociedade. Entretanto, uma análise sobre as fake sciences revela evidências ricas de uma complexa desconfiança dos indivíduos modernos nas instituições de um caótico mundo pós-globalização e de crise democrática.

Atravessamos um momento de crise epistemológica, no qual a relação dos indivíduos com as instituições da modernidade é cada vez mais conturbada. Como resultado, a posição de autoridade institucional do saber ocupada por entidades como a ciência e a medicina não pode ser mais dada como garantida. Grande parte desta descredibilização da ciência é derivada de um momento da própria crise democrática, em que tomadas de decisão baseadas em evidências derivadas de estudos científicos já não tem tanto valor na esfera política. Tem sido cada vez mais recorrentes posições de representantes mundiais que vão de encontro aos conhecimentos científicos em diferentes áreas do conhecimento, como por exemplo, defensa de políticos na produção e distribuição de fosfoetanolamina, como demonstrado neste trabalho, ou de Cloroquina para combate ao Covid-19, mesmo que testes clínicos ainda estejam em fase experimental ${ }^{109}$.

Contudo, pudemos perceber nesta pesquisa que esta crise de credibilidade da ciência não é apenas fruto de irresponsabilidade política, mas também de um afastamento do indivíduo comum das instituições científicas, em que a percepção de controvérsias e conflitos de interesses têm sido a causa mais recorrente deste distanciamento. Evidentemente, não existem consensos científicos, pois a ciência avança a partir de controvérsias dentro do próprio campo científico. Porém, quando estas controvérsias são midiatizadas, outros contornos são adquiridos e a credibilidade científica abalada junto à população. Tanto o movimento antivacina e da fosfoetanolamina se desenvolvem em espaços universitários altamente validados na hierarquia do saber, enquanto o avanço do MMS, difundido inicialmente por integrantes da igreja da cientologia, mostra tanto a falta de regulação para a circulação de conhecimento anticientífico quanto a ascensão do extremismo religioso fruto desta mesma crise epistemológica.

Regulação é o principal problema nas mídias sociais, responsáveis centrais pela amplificação recente destes conteúdos (entre outras teorias da conspiração, fake sciences e movimentos extremistas). Plataformas digitais sociais, como YouTube, WhatsApp e Facebook têm se mostrado, como aponta nosso mapeamento, um grande abrigo para redutos onde fatos alternativos são validados. Torna-se, portanto, necessário discutir a responsabilidade desses espaços para a propagação de desinformação relacionada à ciência. Enquanto as providências tomadas por estes grandes conglomerados de comunicação permanecerem tímidas, maquiando uma postura mercadológica como 'liberdade de expressão', meramente diminuindo recomendações para o conteúdo e pouco moderando efetivamente, os espaços tendem a permanecer favorecendo perigosas práticas de desinformação e má informação. Por outro lado, torna-se importante reconhecer que a regulação não deve vir dessas plataformas, pois a precedência desta autonomia regulatória como responsabilidade destas empresas multinacionais poderá infringir o próprio regime democrático das nações. 
Lidando com um cenário onde a academia disputa autoridade científica com grupos conspiratórios cada vez menos marginais, e com a proliferação de senso comum e de uma sociologia do desconhecimento e ignorância, como aponta José de Souza Martins ${ }^{110}$, tem-se um campo aberto para a indagação científica como forma de manutenção popular da ordem em um mundo inserido em intensas disputas sobre a informação. É necessário enfrentar o desafio de não apenas denunciar, mas buscar entender as causas, encontrar os espaços e decifrar a postura destes grupos que estão envolvidos nas disputas pela informação científica para que a ignorância e o desconhecimento não seja a única certeza possível em uma sociedade repleta de incertezas e desconfianças.

\section{Referências}

1. Lubchenco J. Environmental science in a post-truth world. Fron Ecol Environ. 2017;15(1):3. doi: https:// doi.org/10.1002/fee.1454.

2. Monteiro RA, Santos RLS, Soares TA. Contributions to the study of fake news in portuguese: new corpus and automatic detection results. Int Conf Comp Process Port Language [Internet]. 2018 [cited 2020 Jan 04];11122:324-34. Available from: https://bit.ly/3a2Sk9f.

3. Albuquerque A, Quinan R. Crise epistemológica e teorias da conspiração: o discurso anti-ciência do canal "professor terra plana". Rev Mídia Cotid [Internet]. 2019 [citado em 2020 jan. 04];13(3):83-104. Disponível em: https://periodicos.uff.br/midiaecotidiano/article/view/38088/22345.

4. Boyd-Barrett O. RussiaGate and propaganda: disinformation in the age of social media. [place unknown]: Routledge; 2019.

5. Soares S, Vitelli M. Comunidades epistêmicas e de prática em defesa na Argentina e no Brasil: entre a organicidade e a plasticidade. Carta Intern. 2016;11(3):99-123. doi: https://doi.org/10.21530/ ci.v11n3.2016.510.

6. Ministério confirma 677 casos de sarampo em seis estados do Brasil. G1. [Internet]; 2018. Available from: https://g1.globo.com/bemestar/noticia/2018/07/18/ministerio-confirma-677-casos-de-sarampoem-seis-estados-do-brasil.ghtml.

7. World Health Organization. Poliomyelitis [Internet]. Geneva: The Organization; 2019 July 22 [cited 2020 Feb 01]. Available from: http://www.who.int/news-room/fact-sheets/detail/poliomyelitis.

8. Rivera K. Curando os sintomas conhecidos como Autismo. Niterói: BvBooks; 2016.

9. Grech V. Fake news and post-truth pronouncements in general and in early human development. Early Hum Dev. 2017;115:118-20. doi: https://doi.org/10.1016/j.earlhumdev.2017.09.017.

10. Oliveira T. Autoridade científica em tempos de crise epistêmica: a circulação de teorias da conspiração nas mídias sociais. Anais do 270 Encontro da Compós; 2019 jun. 11-14; Porto Alegre, Brasil. Porto Alegre: PUC-RS; 2019.

11. Recuero R. Conversação em rede: a comunicação mediada pelo computador e redes sociais na Internet. Pelotas: Editora Sulina; 2012.

12. Gauchat G. Politicization of science in the public sphere: a study of public trust in the United States, 1974 to 2010. Am Sociol Rev 2012;77(2):167-87.

13. Mooney C. The republican war on science. New York: Basic Books; 2005.

14. Sztompka P. Trust in science: Robert K. Merton's inspirations. J Class Sociol. 2007;7(2):211-220. doi: https://doi.org/10.1177\%2F1468795X07078038.

15. Slaughter S, Leslie L. Academic capitalism: politics, policies, and the entrepreneurial university. Baltimore: Johns Hopkins University Press; 1997.

16. Clinio A. Ciência aberta na América Latina: duas perspectivas em disputa. Transinformação. $2019 ; 31$. doi: http://dx.doi.org/10.1590/238180889201931e190028.

17. Thaler AD, Shiffman D. Fish t: combating fake science in popular media. Ocean Coastal Manage. 2015;115:88-91. doi: https://doi.org/10.1016/j.ocecoaman.2015.04.005. 
18. Albuquerque A. O combate às fake news nas eleições de 2018: rumo à pós-democracia? In: Paula C, Feres Junior J, organizadores. Eleições 2018 e a crise da democracia brasileira. Rio de Janeiro: Ed. Appris; 2018. p. 98-102.

19. Grech V. Fake news and post-truth pronouncements in general and in early human development. Early Hum Dev. 2017;115:118-20. doi: https://doi.org/10.1016/j.earlhumdev.2017.09.017.

20. Almeida R. A onda quebrada: evangélicos e conservadorismo. Cad Pagu. 2017 June;50. doi: http:// dx.doi.org/10.1590/18094449201700500001.

21. World Health Organization. Poliomyelitis [Internet]. Geneva: The Organization; 2019 July 22 [cited 2020 Feb 01]. Available from: http://www.who.int/news-room/fact-sheets/detail/poliomyelitis.

22. Presidente da SBOC critica suplemento de fosfoetanolamina no "Fantástico" [Internet]. São Paulo: SBOC, Notícias; 2017 fev. 20 [citado em 10 mar. 2020]. Disponível em: https://bit.ly/38QFvNM.

23. Bertoni E. Por que esta substância ameaça crianças com autismo [Internet]. São Paulo: Nexo; 2019 maio 27 [citado em 01 fev. 2020]. Disponível em: https://bit.ly/2IMViCI.

24. Wakefield A. Retracted: ileal-lymphoid-nodular hyperplasia, non-specific colitis, and pervasive developmental disorder in children. Lancet. 1998;375. doi: https://doi.org/10.1016/S01406736(97)11096-0.

25. Kata A. A postmodern Pandora's box: anti-vaccination misinformation on the Internet. Vaccine. 2010;28(7):1709-16. doi: https://doi.org/10.1016/j.vaccine.2009.12.022.

26. Kata A. Anti-vaccine activists, Web 2.0, and the postmodern paradigm-An overview of tactics and tropes used online by the anti-vaccination movement. Vaccine. 2012;30(25):3778-89. doi: https://doi. org/10.1016/j.vaccine.2011.11.112.

27. Cassimiro MC, Bavaresco A, Soares AMM. Filosofia, saúde e bioética no Instituto Oswaldo Cruz: novos desafios do século XXI. Porto Alegre: Editora Fi; 2016.

28. Zebulum JC. O julgamento do caso da fosfoetanolamina e a jurisprudência do Supremo Tribunal Federal. Rev Dir Sanit. 2017;17(3):212-23. doi: https://doi.org/10.11606/issn.2316-9044.v17i3p212-223.

29. Presidência da República (BR), Secretaria-Geral, Subchefia para Assuntos Jurídicos. Lei no 13.269, de 13 de abril de 2016. Autoriza o uso da fosfoetanolamina sintética por pacientes diagnosticados com neoplasia maligna. DOU; 2016 abr. 14 [citado em 2020 fev. 20]. Disponível em: https://bit.ly/2U7lugl.

30. Alves SMC, De Bem I P. Anorexígenos e fosfoetanolamina sintética: a lição que não foi aprendida. Cad Ibero-Americanos Dir Sanit. 2016;6(4):180-3.

31. Presidência da República (BR), Secretaria-Geral, Subchefia para Assuntos Jurídicos. Lei no 6.360, de 23 de setembro de 1976. Dispõe sobre a Vigilância Sanitária a que ficam sujeitos os Medicamentos, as Drogas, os Insumos Farmacêuticos e Correlatos, Cosméticos, Saneantes e Outros Produtos, e dá outras Providências. DOU; 1976 set. 24. [citado em 20 fev. 2020]. Disponível em: http://www.rio.rj.gov.br/ dlstatic/10112/5125745/4208525/LEIN06.360DE23DESETEMBRODE1976.pdf.

32. Presidência da República (BR), Secretaria-Geral, Subchefia para Assuntos Jurídicos. Lei no 5.991, de 17 de dezembro de 1973. Dispõe sobre o Controle Sanitário do Comércio de Drogas, Medicamentos, Insumos Farmacêuticos e Correlatos, e dá outras Providências. DOU; 1973 dez. 19. [citado em 20 fev. 2020]. Disponível em: http://www.planalto.gov.br/ccivil 03/leis/l5991.htm.

33. Presidência da República (BR), Secretaria-Geral, Subchefia para Assuntos Jurídicos. Lei no 9,782, de 26 de janeiro de 1999. Define o Sistema Nacional de Vigilância Sanitária, cria a Agência Nacional de Vigilância Sanitária, e dá outras providências. DOU; 1999 jan. 01. [citado em 20 fev. 2020]. Disponível em: http://www.planalto.gov.br/ccivil 03/leis/19782.htm.

34. Supremo Tribunal Federal (BR). Ação direta de inconstitucionalidade. ADI 5501. No único 005274776.2016.1.00.0000. Brasília: O Supremo; 2016 abr. 15 [citado em 10 jan. 2020]. Disponível em: http:// portal.stf.jus.br/processos/detalhe.asp?incidente $=4966501$.

35. STF suspende lei que autoriza distribuição de fosfoetanolamina, a "pílula do câncer". Consult Jurid [Internet]. 2016 maio [acesso em 2020 jan. 13]. Disponível em: https://www.conjur.com.br/2016mai-19/supremo-suspende-lei-autoriza-distribuicao-pilula-cancer.

36. PGR se manifesta contra comercialização da "pílula do câncer" [Internet]. Brasília: MPF; 2018 out. 31 [citado em 2020 jan. 10]. Disponível em: http://www.mpf.mp.br/pgr/noticias-pgr/pgr-se-manifestacontra-comercializacao-da-201cpilula-do-cancer201d. 
37. Knight PT. Conspiracy Culture: From Kenedy to The X-Files Londres: Routledge; 2001.

38. Smith N, Graham T. Mapping the anti-vaccination movement on Facebook. Inf Commun Soc. 2019;22(9):1310-27. doi: https://doi.org/10.1080/1369118X.2017.1418406.

39. Steensen S. Journalism's epistemic crisis and its solution: disinformation, datafication and source. Journalism. 2019;20(1):185-9.

40. Yochai B, Faris R, Roberts H, Zuckerman E. Study: Breitbart-led right-wing media ecosystem altered broader media agenda. Columbia Journalism Review [Internet]. 2017 [citado em 2020 jan. 10]. Disponível em: https://www.cjr.org/analysis/breitbart-media-trump-harvard-study.php.

41. Mooney C. The Republican War on Science New York: Basic Books; 2005.

42. Van Zoonen, L. I-pistemology: changing truth claims in popular and political culture. Eur J Commun. 2012;27(1):56-67.

43. Oliveira C, Moutat A. From controversy to media controversy: analysis of communication strategies concerning the health risk of growing limousin apples. In: Clavier V, Oliveira JP. Food and health: actor strategies in information and communication; 2019. Vol. 2, p. 29-51.

44. Humble JV. A Solução Mineral Mestre do 30 Milénio. Montreal: Osmora Inc; 2011.

45. Genesis II: church of health and healing [Internet]. Angleton: The church; [2019] [citado em 10 jan. 2020]. Disponível em: https://genesis2church.ch/.

46. Werner A. MMS cura autismo?. Rev Autismo. 2010 maio [acesso em 2020 jan. 03]. Disponível em: https://www.revistaautismo.com.br/nao-categorizado/mms-cura-autismo-andrea-werner/.

47. Old D. Kerri Rivera lança livro e apresenta no Brasil uma nova visão sobre o autismo. Exame [Internet]. 2016 abr. [acesso em 2020 jan. 21];Publicidade Corporativa. Disponível em: https://bit.ly/2xDZWk5.

48. Nisse N, Guyodo G, Manel J, compilers. Evaluation des risques liés à la consommation de produit dénommé "Solution Minérale Miracle" (MMS). Paris: Comite de Coordination de Toxicovigilance; 2010 [accès à 2020 janv 04]. Disponible en: http://www.centres-antipoison.net/CCTV/Rapport CCTV Solution minerale miracle 2010.pdf.

49. Burke D, Zakhary B, Pinelis E. Acute hemolysis following an overdose of miracle mineral solution in a patient with normal glucose-6-phosphate dehydrogenase levels. Chest. 2014;146(4) doi: https://doi. org/10.1378/chest.1988668

50. Ferreira L. Anvisa proíbe remédio que vendia falsa cura para Aids e autismo [Internet]. O Globo (Globo S/A.). 2019 maio 05 [acesso em 2020 jan. 29]:Sociedade. Disponível em: https://glo.bo/2U4CZOp.

51. Arbulu R. Postagens que prometem milagres de saúde serão rebaixadas pelo Facebook [Internet]. [local desconhecido]: CanalTech; 2019 jul. 02. Disponível em: https://canaltech.com.br/redes-sociais/ postagens-que-prometem-milagres-de-saude-serao-rebaixadas-pelo-facebook-143161/.

52. Rosenstiel T, Sonderman J, Loker K, Ivancin M, Kjarval N. Twitter and the news: how people use the social network to learn about the world [Internet]. Arlington: American Press Institute; 2015 Sep 01 [access 2020 Jan 05]. Available from: https://bit.ly/3d9KYTg.

53. Newman N, Fletcher R, Kalogeropoulos A, Levy DAL, Nielsen RK. Reuters Institute Digital News Report 2017. Reuters Institute Digital News Report 2017 [Internet]. Oxford: Reuters Institute, University of Oxford; 2017 [access 2020 Jan 07]. Available from: https://bit.ly/2vl8USn.

54. Recuero R. "Deu no Twitter, alguém confirma?" Funções do jornalismo na era das redes sociais. In: Anais do $9^{\circ}$ Encontro Nacional de Pesquisadores em Jornalismo; 2011 nov. 11; Rio de Janeiro, Brasil. Rio de Janeiro: UFRJ; 2011.

55. Tavares C. A crise do modelo tradicional de jornalismo: reconfiguração da prática profissional na redação da Gazeta do Povo [tese]. Niterói: UFF; 2019.

56. Nielsen RK. The business of news. In: Witschge T, Anderson CW, Domingo D, Herminda A, editors. The Sage handbook of digital journalism. Los Angeles: Sage; 2016. p. 51-67.

57. Van Dijck J, Poell T. Understanding social media logic. Media Commun. 2013;1(1):2-14. doi: https://doi. org/10.12924/mac2013.01010002.

58. Burki T. Vaccine misinformation and social media. Lancet. 2019;1(6):PE258-E259. doi: https://doi. org/10.1016/S2589-7500(19)30136-0. 
59. Steffens MS, G. Dunn AG, Wiley KE, Leask J. How organisations promoting vaccination respond to misinformation on social media: a qualitative investigation. BMC Public Health. 2019;19(1):1348. doi: https://doi.org/10.1186/s12889-019-7659-3.

60. Hoffman BL, Felter EM, Chu KH, Shensa A, Williams D, Himmel R, et al. The emerging landscape of antivaccination sentiment on Facebook. J Adolescent Health. 2019 Feb;64(2)Supp:S136. doi: https://doi. org/10.1016/j.vaccine.2019.03.003.

61. Zelizer B. Covering the body: the Kennedy assassination, the media, and the shaping of collective memory. Chicago: University of Chicago Press; 1992.

62. Aupers S. 'Trust no one': modernization, paranoia and conspiracy culture. Eur J Commun. 2012;27(1):22-34. doi: 10.1177/0267323111433566.

63. Signates L. Epistemologia e comunicabilidade: as crises das ciências, ante a perspectiva da centralidade do conceito de comunicação. Comun Inf. 2012 jul./dez.;15(2):133-48.

64. Nisbet E, Cooper K, Garret R. The partisan brain: how dissonant science messages lead conservatives and liberals to (dis) trust science. Aa Am Acad Polit S S. 2015;658(1):36-66.

65. Gauchat G. Politicization of science in the public sphere: a study of public trust in the United States, 1974 to 2010. American Sociol Rev. 2012;77(2):167-87.

66. Balmas M. When fake news becomes real: combined exposure to multiple news sources and political attitudes of inefficacy, alienation and cynicism. Commun Res. 2012;41(3):430-54. doi: $10.1177 / 0093650212453600$.

67. Tandoc E, Wei L Z, Ling R. Defining "fake news": a typology of scholarly definitions. Digit Journalism. 2018;6(2):137-53. doi: https://doi.org/10.1080/21670811.2017.1360143.

68. Bakir V, McStay A. Fake news and the economy of emotions: problems, causes, solutions. Digit Journalism. 2017;6(2):154-75. doi: https://doi.org/10.1080/21670811.2017.1345645.

69. Khaldarova I, Pantti Mervi. The narrative battle over the Ukrainian conflict. Journalism Pract. 2016;10(7):891-901. doi: https://doi.org/10.1080/17512786.2016.1163237.

70. Egelhofer J L, Lecheler S. Fake news as a two-dimensional phenomenon: a framework and research agenda. Ann Int Commun Assoc. 2019;43(2). doi: https://doi.org/10.1080/23808985.2019.1602782.

71. Dickson EJ. A guide to 17 anti-vaccination celebrities. Rolling Stone [Internet]. 2019 June 19 [cited 2020 Jan. 24]. Available from: https://bit.ly/39Sye14.

72. Entis L. Donald Trump has long linked autism to vaccines. He isn't stopping now that he's president. Fortune [Internet]. 2019 Feb 16 [cited 2020 Jan. 24]. Available from: https://bit.ly/2U8WR2O.

73. Olavo de Carvalho, guru de Bolsonaro, é contra vacinação infantil [Internet]. São Paulo: Catraca Livre; 2018 nov. 27 [acesso em 2019 dez. 14]. Disponível em: https://bit.ly/3aUJXwd.

74. Bolsonaro corta $\mathrm{R} \$ 500$ milhões no programa nacional de imunização. Forum [Internet]. 2019 set. 12 [citado em 2019 dez. 14]. Disponível em: https://bit.ly/2wSRjBV.

75. Broniatowski $D$ et al. Weaponized health communication: Twitter bots and Russian trolls amplify the vaccine debate. Am J Public Health. 2019;108(10):1378-1384. doi: https://dx.doi.org/10.2105\%2FAJ PH.2018.304567.

76. Camargo Jr K, Grant R. Public health, science, and policy debate: being right is not enough. Am J Public Health. 2015 Feb;105(2):232-35. doi: https://dx.doi.org/10.2105\%2FAJPH.2014.302241

77. Vargo C J, Hopp T. Socioeconomic status, social capital, and partisan polarity as predictors of political incivility on twitter: a congressional district-level analysis. Soc Sc Comp Rev. 2016 Aug;35(1). doi:https://doi.org/10.1177\%2F0894439315602858

78. Roose K, Conger K. YouTube to remove thousands of videos pushing extreme views [Internet]. The New York Times (The New York Times Co.). 2019 June 05 [acessaccess 2019 Dec 14]. Available from: https://nyti.ms/33kCKTS.

79. Golgowski N. Facebook e YouTube afrouxam regras para políticos e facilitam disseminação de fake News [Internet]. [local desconhecido]: Huffpost; 2019 set. 26 [acesso em 2019 dez. 14]. Disponível em: https://bit.ly/2QfEMiC. 
80. Willets M. Mark Zuckerberg Posts Pro-Vaccine Photo, Incurs Wrath [Internet]. California: Parents; 2018 [access 2019 Dec 14]. Available from: https://bit.ly/2Qdu2SO.

81. Nunez M. Mark Zuckerberg's answer to an anti-vaxxer question highlights Facebook's problematic response to misinformation [Internet]. Forbes, 2019 out 26 [citado em 20 fev 2020]. Available from: https://www.forbes.com/sites/mnunez/2019/10/23/mark-zuckerbergs-answer-to-an-anti-vaxxerquestion-highlights-facebooks-problematic-response-to-misinformation/\#71f13e1d70b7.

82. Camerini L, Diviane N, Tardini S. Health virtual communities: is the self lost in the net?. Soc Semiots. 2010;20(1):87-102. doi: https://doi.org/10.1080/10350330903507230.

83. Percheski C, Hargittai E. Health information-seeking in the digital age. J Am Coll Health 2011 March;59(5):379-86. Doi: https://doi.org/10.1080/07448481.2010.513406.

84. Vaterlaus JM, Pattern EV, Roche C, Young J A. \#Gettinghealthy: the perceived influence of social media on young adult health behaviors. Comp Hum Behav. 2015;45:151-57. doi: https://doi.org/10.1016/j. chb.2014.12.013.

85. Smith N, Wickes R, Underwood M. Managing a marginalised identity in pro-anorexia and fat acceptance cybercommunities. J Soc. 2015;51(4):950-67. doi: https://doi.org/10.1177/1440783313486220.

86. Oh HJ, Ozkaya E, LaRose R. How does online social networking enhance life satisfaction? The relationships among online supportive interaction, affect, perceived social support, sense of community, and life satisfaction. Comp Hum Behav. 2014;30:69-78. doi: https://doi.org/10.1016/j.chb.2013.07.053.

87. etsch $\mathrm{C}$ et al. Opportunities and challenges of Web 2.0 for vaccination decisions. Vaccine. 2012;30(25):3727-33. doi: https://doi.org/10.1016/j.vaccine.2012.02.025.

88. Marconi MA, Lakatos EM. Técnicas de pesquisa. São Paulo: Atlas; 2002.

89. Bardin L. Análise de conteúdo. Lisboa: Edições 70; 1977.

90. Grouverman A, Kollanyi B, Howard P, Barash V, Lederer T. Climate change consensus and skepticism: mapping climate change dialogue on Twitter and Facebook Comprop Data Memo [Internet]. 2018 [access 2019 Dec 14]. Available from: https://comprop.oii.ox.ac.uk/research/climate-change/.

91. Parra J. MMS o clorito de sodio: el veneno disfrazado de cura milagrosa para el cáncer o el autismo [Internet]. Concepción: Biobiochile.cl; 2019 junio 29 [acesso em 2020 marzo 10]. Disponible: https:// bit.Iy/3cVFATw.

92. O lado obscuro das vacinas. As vacinas são realmente seguras [Internet]. São Paulo: Facebook; [2019?] [citado em 15 dez 2019. Disponível em: https://www.facebook.com/oladoobscurodasvacinas/.

93. Câncer tem cura! Fosfoetaetanolamina sintética Dr. Gilberto Chierice [Internet]. São Paulo: Facebook; [2019?]. [acesso em 2019 dez. 15]. Disponível em: https://www.facebook.com/ FosfoetanolaminaTestimonials/.

94. Fostfoetanolamina [Internet]. São Paulo: Facebook; [2019?] [acesso em 2019 dez. 15]. Disponível em: https://www.facebook.com/Fosfoetanolamina-692750387492873/.

95. Fostoetanolamina: a esperança proibida para a cura do câncer [Internet]. São Paulo: Facebook; [2019?] [acesso em 2019 dez. 15]. Disponível em: https://www.facebook.com/liberaanvisa.

96. Fostoetanolamina: quem tem câncer, tem pressa [Internet]. São Paulo: Facebook; [2019?] [acesso em 2019 dez. 15]. Disponível em: https://www.facebook.com/fosfoetanolaminaoficial/.

97. Fosfoetanolamina sintética Goiás [Internet]. São Paulo: Facebook; [2019?] [acesso em 2019 dez. 15]. Disponível em: https://www.facebook.com/fosfoetanolaminasinteticagoias/.

98. Fosfoetanolamina sintética: pela continuidade da pesquisa contra o câncer [Internet]. São Paulo: Facebook; [2019?] [acesso em 2019 dez. 15]. Disponível em: https://www.facebook.com/fosfoamina.

99. MMS: solução mineral milagrosa [Internet]. São Paulo: Facebook; [2019?] [acesso em 2019 dez. 15]. Disponível em: https://www.facebook.com/Mms-solu\%C3\%A7\%C3\%A3o-mineralmilagrosa-192056201487385/.

100. Instituto: fosfoetanolamina e tratamentos complementares [Internet]. São Paulo: Facebook; [2019?] [acesso em 2019 dez. 15]. Disponível em: https://www.facebook.com/institutoeseudireitosaber/.

101. É o seu direito de saber: informação e qualidade de vida [Internet]. 2015 [acesso em 2019 dez. 15]. Disponível em: https://eseudireitosaber.com.br/. 
102. Fosfoetanolamina [Internet]. São Paulo: Facebook; [2019?] [acesso em 2019 dez. 15]. Disponível em: https://www.facebook.com/fosfoetalonaminacancer/.

103. Dr. Renato Meneguelo [Internet] São Paulo: Facebook; [2019?] [acesso em 2019 dez. 15]. Disponível em: https://www.facebook.com/DrRenatoMeneguelo.

104. Renato Meneguelo [Currículo Lattes] [Internet]. Brasília: CNPq; 2018 [acesso em 2019 dez. 15]. Disponível em: http://lattes.cnpq.br/9925551979058002.

105. Diego Rodriguez [Internet]. São Paulo: Facebook; [2019?] [acesso em 2019 dez. 15]. Disponível em: https://www.facebook.com/pg/DieguitoPQDOficial/.

106. CPI diz que testes da pílula do câncer teve falhas e pede nova pesquisa [Internet]. São Paulo: UOL; 2018 abr. 04 [acesso em 2019 dez. 15]. Disponível em: https://bit.ly/2Qhv5A7.

107. Jeff Vaz - Anjo Negro [Internet]. São Paulo: Facebook; [2019?] [acesso em 2019 dez. 15]. https://pt-br. facebook.com/DRJEFFVAZADVOGADO.

108. Kuhn TS. A estrutura das revoluções científicas. 5. ed. São Paulo: Perspectiva; 1997

109. Martins JS. Estamos em face da ignorância moderna [Internet]. Valor Econômico, 2019 nov 10 [citado em 2019 dez. 15]. Disponível em: https://valor.globo.com/eu-e/coluna/jose-de-souza-martins-estamosem-face-da-ignorancia-moderna.ghtml.

110. Coronavírus: Bolsonaro diz que Exército vai ampliar produção de cloroquina [Internet]. 0 Globo. 21 de mar. 2020 [acesso em 2020 mar. 23). Disponível em: https://oglobo.globo.com/sociedade/coronavirusbolsonaro-diz-que-exercito-vai-ampliar-producao-de-cloroquina-1-24320671. 